\title{
Implementation of Visualization and Modeling Technologies for Transportation Construction
}

\author{
Christofer M. Harper ${ }^{1}$, Daniel Tran², Edward Jaselskis ${ }^{3}$ \\ 1. Colorado State University, Fort Collins, CO, 80523 USA \\ 2. University of Kansas, Lawrence, KS, 66045 USA \\ 3. North Carolina State University, Raleigh, NC, 27695 USA \\ E-mail: chris.harper@colostate.edu; daniel.tran@ku.edu; ejjasels@ncsu.edu
}

Received: 3 August 2021; Accepted: 15 November 2021; Available online: 31 December 2021

\begin{abstract}
State departments of transportation (DOTs) increasingly use visualization and modeling technologies for delivering transportation projects across the United States. Advanced and innovative technologies have the ability to improve various construction processes and tasks while making the construction process more efficient and productive. Visualization and modeling technologies, which include building information modeling for infrastructure, light detection and ranging, virtual reality, and augmented reality, are becoming more commonplace in transportation construction. Yet, the use of these technologies varies among state DOTs. The intent of this study is to investigate the use of visualization and modeling technologies for transportation construction. This study employed a triangulation research methodology including an extensive literature review, survey questionnaire of DOTs, and seven case studies. Results of the study show that $92 \%$ of state DOTs use visualization and modeling technologies for construction. Then, 81\% of DOTs use visualization and modeling technologies for constructability reviews, $38 \%$ use them for documentation of as-builts and simulating bridge and structure construction, and $35 \%$ use them for quality management, inspections, and monitoring progress of work. The main barriers to using visualization and modeling technologies include legal concerns with using digital models as contract documents, incompatibilities in software and hardware between the DOTs and contracted parties, and the appropriate knowledge, skills, and abilities required to use visualization and modeling technologies for construction. The findings from this study provides valuable information for state DOTs to approach their implementation and use of visualization and modeling technologies for transportation construction delivery.

Keywords: Visualization and modeling technologies; Transportation construction; State transportation agencies; Digital construction delivery.
\end{abstract}

\section{Introduction}

State departments of transportation (DOTs) are increasingly using visualization and modeling technologies to deliver transportation construction projects across the United States. As the transportation construction sector adopts more information technologies into project delivery, DOTs have an opportunity to improve project performance regarding cost, schedule, and quality. The Federal Highway Administration (FHWA) Every Day Counts initiatives (EDC-3 and EDC-4 specifically) encourages the use of advanced and emerging digital, visualization, and modeling technologies, such as e-construction, building information modeling for infrastructure, light detection and radar (LiDAR), virtual reality (VR), and augmented reality (AR).

Digital solutions for transportation construction are tools for collecting and sharing information that helps a project team to be more transparent and collaborative, improves the quality of a project, while arriving at costeffective project outcomes [1]. As productivity growth has been limited since the 1980s, technologies present a way to be more efficient in the design and construction of projects. Previous studies have found a positive correlation between the extent that an industry digitizes itself and productivity improvements. Adopting effective practices in the construction industry to promote the use of visualization technologies, along with the use of advanced materials, and automation, has the potential to grow construction project productivity by up to $10 \%$, which results in approximately 5\% cost savings [2]. On the other hand, continued use of paper-based processes for project planning and delivery is a contributing factor to a lack of productivity improvements and constrains innovation [3,4]. A lack of digitalization use also may impact information sharing, which leads to challenges and errors in data analyses, progress reporting, and other processes. To assist with moving from paper-based processes to digital, Agarwal et al. [5] developed general digital solutions for delivering infrastructure construction projects, as shown in Table 1. 
Table 1. General digital solutions for construction delivery processes [5]

\begin{tabular}{ll}
\hline Process & Description \\
\hline Design Management & View digital drawings and models on site using mobile devices \\
Scheduling & Update drawings in the field with markups, annotations, and hyperlinks \\
& Create, assign, and prioritize tasks in real time \\
& Track progress in real time \\
& Distribute work plans and schedule to field personnel in real time \\
& Issue notifications to subcontractors using mobile devices in real time \\
Materials Management & Identify, track, and locate materials and equipment across the supply chain \\
Crew Location & Provide real-time status updates on total crew deployed across work fronts, number \\
& of active working hours, entry into unauthorized areas, and others \\
Quality Control & Remote site inspections using photos/videos and tags shared through mobile \\
& devices in the field \\
Contract Management & Update and track punch lists to expedite project close-out \\
& Update and track contract-compliance checklists \\
& Maintain standardized communication checklists \\
Performance & Provide updated record of all client and contractor communications \\
Management & Monitor progress and performance across teams and work areas \\
& Provide automated dashboards created from field data \\
Document Management & Offer staffing updates and past reports generated on handheld devices \\
& Upload and distribute documents for reviewing, editing, and recording all decisions \\
& Allow universal project search across any phase \\
\hline
\end{tabular}

Previous research has investigated various visualization and modeling technologies and their applied uses in construction. However, the implementation and application of these technologies by state DOTs for highway construction delivery has been explored on a very limited based. This could be an issue as transportation projects currently use less technologies than vertical building construction and therefore transportation projects are missing the potential benefits of implementing technologies to be more efficient in the project delivery process. The objective of this study then is to investigate the implementation, use, and challenges of visualization and modeling technologies for delivering much needed highway construction projects. The outcomes of this study are to provide how state DOTs are using visualization and modeling technologies along with the challenges that they have experienced in implementing and using these technologies. This information can be helpful for transportation agencies to evaluate and consider the use of visualization and modeling technologies for delivering transportation construction project in a more efficient manner.

\section{Overview of visualization and modeling technologies}

For many years, DOTs used paper-based documentation approaches for contract administration and construction management of highway projects. More recently, there has been a shift in the use of digital technologies for delivering construction projects. The FHWA's Every Day Counts initiative (EDC-3) informed DOTs on e-construction technologies that focused on implementing digital electronic signatures, electronic communication, secure file sharing, mobile devices in the field, and web-hosted data archival and retrieval systems. EDC-3 found that, in addition to time and cost savings, the digital construction processes allow for realtime information sharing, faster decision-making and approvals, increased accuracy, and enhanced document tracking, all while increasing transparency between the DOT and contracted parties [6]. Furthermore, EDC-4 promotes e-construction and digital technologies as practices that are used to deliver transportation improvements smarter and faster through enhanced partnering and communication within the project team [7].

A wide range of technologies exists that directly link to digitalization and visualization of construction delivery. Some of the more frequently used visualization and modeling technologies and applications by DOTs currently are light detection and ranging (LiDAR), building information modeling (BIM), and virtual reality (VR) and augmented reality (AR).

\subsection{Light detection and ranging}

LiDAR is an optical remote sensing technology used for measuring the distance between a surface and its sensing units. LiDAR has increased in use due to its ability to create accurate three-dimensional (3D) models of any surface within visual sight of the sensing unit. Many DOTs have adopted practical uses of LiDAR technology 
for highway construction-related applications, such as establishing the original ground and contours and locating utilities $[8,9,10]$. There are three primary LiDAR applications:

1) Static LiDAR - system mounted at a single location that collects highly accurate data, but is slower than other applications, and potentially exposes workers to traffic and other hazards [9].

2) Mobile LiDAR - system attached to a mobile object such as a vehicle or heavy equipment, which uses LiDAR, inertial navigation systems, and global positioning system (GPS) to capture roadway markings, assets, and cross sections [10].

3) Airborne LiDAR - aircraft installed systems that can travel at speeds up to 115 miles per hour at elevations of no more than 1,600 feet [11].

A key benefit of LiDAR technology is that its acquired data is useful for various applications. The data collected using LiDAR is in a digital point cloud format that allows for analyses of the data for mapping highway construction facilities and assets $[12,13]$. Mining of the collected data for information can serve as suitable inputs for various construction related design and modeling applications performed by DOTs such as 3D digitized models and information for automated machine guidance (AMG). National Cooperative Highway Research program (NCHRP) Report 748 [8] described various mobile LiDAR applications for delivering highway construction projects as follows:

1) As-built and maintenance documentation-Integration of LiDAR data into a centralized database that is continuously updated for future planning and construction.

2) Pavement smoothness and quality determination — LiDAR data collected at high resolutions can be used to evaluate pavement smoothness and quality.

3) Construction automation and quality control—Change detection and deviation analysis software uses digital models to identify deviations from LiDAR point clouds for construction quality control.

4) Performing quantity take-off-LiDAR data is used to calculate lengths, areas, or volumes of construction quantities.

5) Virtual and 3D Design — LiDAR data can be used for clash detection by checking for intersections of proposed objects with existing objects modeled in the point cloud.

6) Inspections-LiDAR can provide overall geometric information and an overall condition assessment of various transportation infrastructure assets.

\subsection{Building information modeling}

BIM is the intensive process of developing and using a computer-generated model to simulate the phases of a construction project digitally, which can include modeling and simulating the planning, design, construction, and maintenance and operation of transportation facilities. BIM models have many applications such as 3D rendering of a project or components of a project, while construction plans and shop drawings can be extracted and building codes reviewed through analysis of object parameters [5].

According to Dodge Data \& Analytics [14], the level of adoption of BIM for projects in different infrastructure sectors from 2009 to 2013 (see Figure 1). Specifically, the use of BIM more than doubled between 2009 and 2013 from $20 \%$ to $56 \%$ for bridges, roads, and highways projects.

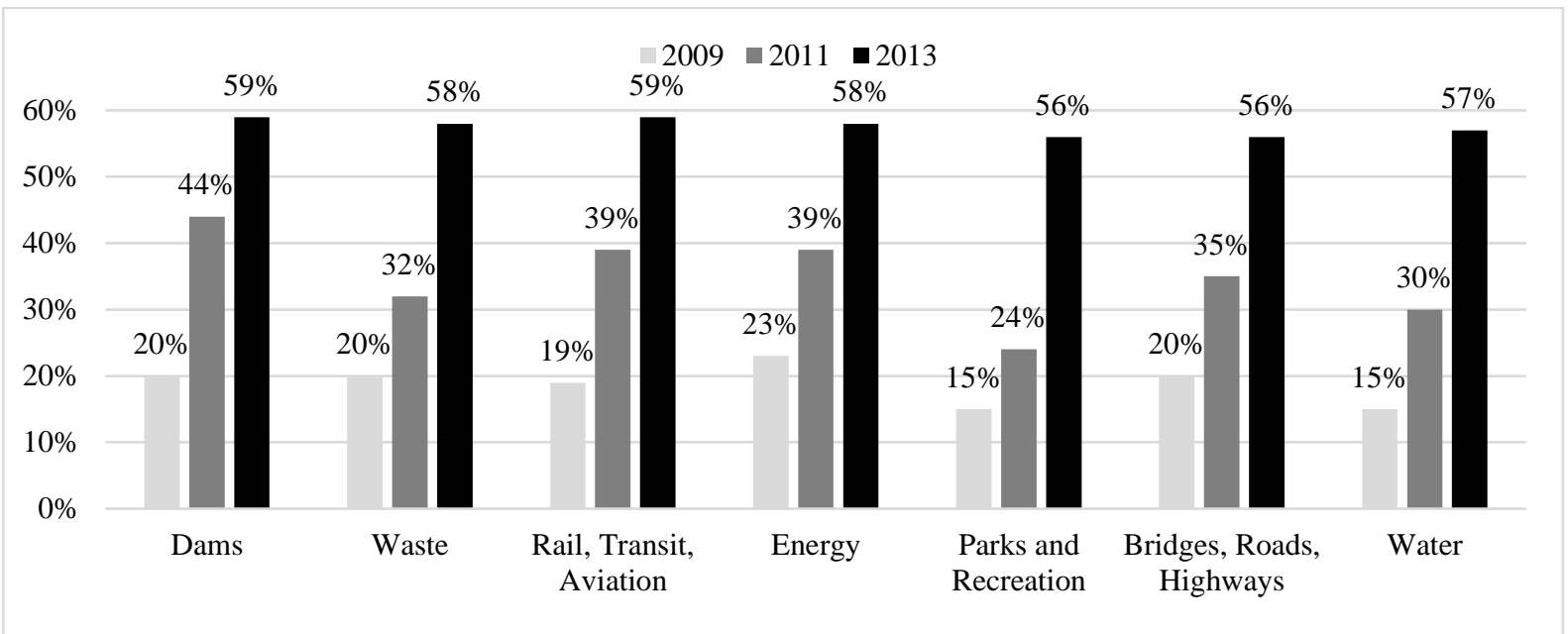

Figure 1. BIM adoption for different types of infrastructure projects

FHWA emphasized the used of 3D engineered models for design and construction in its EDC-2 and EDC-3 initiatives, which showed that visualization, modeling, and simulation efforts facilitate communication between 
multiple stakeholders and allowed contractors to streamline construction schedules, producing significant cost and schedule advantages $[6,7,15]$. Some key benefits realized from the use of 3D models include:

1) Improved project delivery by accelerating construction progress, making construction more accurate and cost-effective, and increasing safety on the job site;

2) Enriched communication between key stakeholder communities (e.g., owner, public, consultants, contractor, utility companies, prefabricators, and material suppliers);

3) Enhanced clash detection and identification of possible errors and inconsistencies in design before construction; and

4) Improved visualization of subgrade features and potential utility conflicts $[6,7,15]$.

The national cooperative highway research program (NCHRP) report 831 [16] noted the perceived benefits and challenges from the use of BIM for highways. Perceived benefits of BIM include promoting early decision making; mitigating risk and enhancing validation of the project; and providing better communication throughout the project. The challenges noted in regards to the use of BIM are cost associated with BIM adaptation, especially set up costs if multiple technologies are used; more work and fees at risk early in the project development process; and lack of buy-in. These benefits and challenges of BIM vary and occur on a project-by-project basis [16].

Furthermore, adoption of BIM in the construction industry, and specifically in transportation construction has been slow. Implementation barriers exist that impede agencies from investigating and using BIM for transportation construction. According to Ahmed [17], the common barriers to implementation of BIM include resistance to change, changes the traditional ways of constructing projects, training expensive and learning curve, high cost of software, and lack of awareness on what benefits agencies can gain from the use of BIM.

\subsection{Virtual reality and augmented reality}

VR technology superimposes a computer-generated image to give a user a view of the real world, thus providing a composite view that isolates the user's sensory receptors (e.g., eyes and ears) from the real physical world [18]. VR has been used within the construction industry for many different applications such as design development, collaborative simulations, and as a tool to improve construction processes. VR enhanced the building design process as it provides a $3 \mathrm{D}$ visualization that a user can manipulate in real-time and collaboratively explore different stages of the construction process $[19,20]$. In contrast to VR, AR creates an environment where a user has a superimposed computer-generated view of a real-world scene. AR consists of a live, imitative version of the real world - with the capacity to add certain elements to the simulated landscape. AR preserves the user's awareness of the real environment by compositing the real world and the virtual contents [21].

A VR or AR system, typically referred to as the hardware components, software, and algorithms, has various applications in the construction industry. Rankohi and Waugh [22] showed that field workers and project managers have high interest in using VR and AR technologies during the project construction phase mainly to monitor progress and detect defects or clashes in the placement of work. Shin and Dunston [23] discussed the potential of AR applications in eight work tasks of a construction project: layout, excavation, positioning, inspection, coordination, supervision, commenting, and strategizing. VR and AR technologies can also be integrated with BIM to create a seamless interaction between the design and the construction work [3]. Previous research show that VR and AR allow users to find the differences between an as-designed 3D model and an as-built facility [24]. Further, other researchers investigated and then implemented a system for visualizing performance metrics to represent progress deviations through the superimposition of 4D as-planned models over time-lapsed job site photographs [25].

It is important to note that although VR and AR technologies have a number of applications to improve construction performance and received considerable attention within research communities, they are still relatively new in the highway construction industry. In fact, Pistorius [3] indicated that the construction industry has so far only “dabbled in the use of VR and AR to aid construction projects.” However, as less expensive and higher quality visualization options come to market, many expect that VR and AR technologies will rapidly increase in use for construction projects in the near future [3]. Specifically, VR and AR technologies are increasing in their use for specific areas of construction, including design and construction inspections [26].

\section{Methodology}

The main objective of this study is to investigate the current state of practices of implementing visualization and modeling technologies for highway construction delivery. To achieve this objective, this study employed triangulation research methodology including three primary research tasks. First, the authors conducted a literature review to synthesize the relevant information in regards to the types and uses of visualization and modeling technologies as they pertain to highway construction projects. Second, a survey questionnaire was developed and distributed to DOTs for collecting information on visualization and modeling technologies in highway construction. Lastly, select DOTs were used as the basis for conducting case studies on their uses, benefits, 
challenges, and lessons learned of employing visualization and modeling technologies for highway construction projects.

\subsection{Literature review}

A comprehensive literature review was conducted exploring visualization and modeling technologies and the associated practices in use for highway construction. The literature review entailed searching for relevant journal articles and conference proceedings using Google Scholar, Engineering Village 2, and the Colorado State University Library system. Further literature in the form of reports and technical briefs were collected from transportation websites including the US DOT and the Federal Highway Administration. Finally, the team also collected and reviewed relevant information from individual DOT websites. The literature collected helped to inform how to approach this study and to develop the data collection tools.

\subsection{Survey of DOTs}

Using the information collected from the literature review, a questionnaire was developed to survey DOTs. The purpose of the survey was to gather information on current nationwide practices and uses of visualization and modeling technologies and to identify DOTs with knowledge and experience that warrant additional investigation as case studies. Also, the questionnaire allowed DOT respondents to attach relevant documents, or reference specific websites that offer information on current visualization and modeling technologies in use. Examples of the survey questionnaire are as follows:

1) What types of highway construction projects benefits from using visualization and modeling technologies?

2) Which visualization and modeling technologies has your DOT used to deliver highway construction projects?

3) How are visualization and modeling technologies used to deliver highway construction projects at your DOT?

4) How frequently does your DOT use visualization and modeling technologies to deliver highway construction projects?

5) What are some challenges and lessons learned in implementing the use of visualization and modeling technologies for construction delivery at your DOT?

6) What project stakeholders directly use visualization and modeling technologies during construction of highway projects?

The survey questionnaire was distributed electronically to members of the American Association of State Highway and Transportation Officials (AASHTO) Committee on Construction, which includes representatives from 50 state DOTs. The authors requested that the AASHTO Committee on Construction member contacted at each DOT to either complete the survey or forward it to the person or people best qualified to respond to the survey. The objective of the survey distribution was to collect one comprehensive and quality response from each DOT. After sending reminder requests to participate in the survey, 41 completed questionnaires were obtained from DOTs (an 82\% response rate). Out of the 41 DOT responses, 26 are implementing, nine are considering implementation, and six are not implementing visualization and modeling technologies for highway construction.

\subsection{Case studies}

The survey questionnaire helped to draw conclusions on the use of visualization and modeling technologies in highway construction, and to identify suitable DOTs for the case studies. Of the DOTs identified, the authors conducted seven in-depth case studies to gather specific information on the use of visualization and modeling technologies during the construction phase of highway projects.

\subsubsection{Selection of case studies}

Data from the survey and literature review were used to select the DOTs for further study. The authors used the following selection criteria:

1) Experience with the use of visualization and modeling technologies for highway construction;

2) Comprehensiveness and availability of visualization and modeling technology documents and data; and

3) The willingness of agency personnel to participate in the study.

Participation involved conducting interviews with DOT staff that use visualization and modeling technologies, collecting visualization and modeling documents and reports, and reviewing the findings for accuracy. The following case study protocol was used:

1) Contact DOT representatives to orient the research team to the DOT and request participation and access to staff knowledgeable about visualization and modeling technologies for highway construction.

2) Perform interviews with agency staff to identify the uses, benefits, challenges, and lessons learned of using visualization and modeling technologies for construction delivery.

3) Collect visualization and modeling documents and reports.

4) Follow up with DOT representatives interviewed to verify the collected findings. 
Using Oppenheim [27] as a research guide to develop the case study questions, the authors proceeded with performing the case studies using the protocol outline above and the developed questions through structured interviews, which were conducted in accordance with the Government Accountability Office procedures [28]. The seven DOTs that agreed to participate in this study are Minnesota, New York State, Ohio, Pennsylvania, Utah, Washington State, and Wisconsin.

\subsubsection{Minnesota DOT}

The Minnesota DOT employs BIM, LiDAR, VR, AR, and wearable visualization devices. These visualization and modeling technologies assist Minnesota DOT in performing constructability reviews, documenting digital asbuilt models, simulating construction of bridges and structures, using virtual design and construction, managing quality, and assisting with construction inspections. While Minnesota DOT began investigating the use of modeling more than a decade ago, Minnesota DOT has advanced its use in visualization and modeling technologies within the past few years. The advancement in Minnesota DOT's use is attributed to the Office of Construction and Innovative Contracting (OCIC), which promotes the use of visualization and modeling technologies. Furthermore, Minnesota DOT upper management created the position of program delivery software manager. This manager's responsibilities are to advance the use of digital modeling, simulations, VR, and AR, and to provide leadership and support in the use of software and hardware for digital project management and delivery.

\subsubsection{New York State DOT}

The importance of the roadway system in New York, paired with the limited DOT annual budget, means that the New York State DOT needs to operate as efficiently as possible. As a way to improve construction efficiency, New York State DOT uses or encourages their contractors to use visualization and modeling technologies. The New York State DOT uses BIM, LiDAR, and virtual prototyping technologies to perform constructability reviews, document as-built models, simulate bridges and structures construction, manage quality, and assist with construction inspections and project controls.

\subsubsection{Ohio DOT}

The use of technologies varies in its implementation at Ohio DOT, with the use of modeling and visualization technologies the most mature, although considered to be in the pilot stage. Ohio DOT uses BIM and LiDAR visualization and modeling technologies to assist with highway construction tasks including constructability reviews, construction simulations of bridges and structures, quality control/quality assurance, and construction inspections. As part of their e-construction initiative, Ohio DOT plans to move from traditional printed plans to digital 3D and 4D models and simulations within the next five years. Currently, Ohio DOT uses visualization and modeling technologies for specific projects that involve complex scope, several reinforced structures, and projects located in urban areas with high traffic volumes.

\subsubsection{Pennsylvania DOT}

The Pennsylvania DOT utilizes BIM and LiDAR visualization and modeling technologies for highway construction projects. These technologies assist Pennsylvania DOT with constructability reviews, as-built documentation, and verifying progress and completion of work for contractual purposes. Highway projects with large scopes of work typically justify the use of visualization and modeling technologies at Pennsylvania DOT, yet their use of visualization and modeling technologies has been limited to projects with large earthwork quantities in recent years. When Pennsylvania DOT develops a digital model for a project, they provide the model for contractors to use. Contractors then use the model for estimating quantities for bidding purposes, detailing the means and methods of construction, and tracking the progress of work during construction.

\subsubsection{Utah DOT}

The Utah DOT employs technologies during project delivery to improve efficiency. Utah DOT consistently looks for ways to make agency staff, consultants, contractors, and inspectors more efficient. Therefore, the Utah DOT has recently advanced its use of visualization and modeling technologies, especially for highway construction delivery. Using BIM and LiDAR, Utah DOT can perform constructability reviews, simulate bridge construction, locate utilities, verify work progress and completion, and assist with construction inspections. Utah DOT implements model-based design and construction with digital transfer of information to produce an optimal design, which improves information transfer, decision-making, and efficiency.

\subsubsection{Washington State DOT}

Washington State DOT has six core values of safety, engagement, innovation, integrity, leadership, and sustainability. The use of technologies for construction delivery enhances these values and makes the use of technologies critical to their business operations. In terms of visualization and modeling technologies, Washington 
State DOT uses BIM and LiDAR, which are used in constructability reviews and to communicate digital information. Within the Washington State DOT, the Visual Engineering Resource Group (VERG) develops digital models, simulations, videos, and other graphical systems to provide clear and effective communication of a project's development, design, and construction. The VERG uses visualizations to explain complex design options, construction processes, or context-sensitive solutions to stakeholders. The VERG then develops simulations of construction and the final product.

\subsubsection{Wisconsin DOT}

One of Wisconsin DOT's core values is improvement, which emphasizes finding innovative ways to provide better products and services. With that in mind, technologies play a critical role in the construction and preservation of highway facilities. Wisconsin DOT employs BIM, LiDAR, VR, and AR for constructability reviews, fabricating structural components, virtual design and construction, quality control/quality assurance, assisting with construction inspections, and communicating with stakeholders and the traveling public. Wisconsin DOT utilizes two different approaches to using visualization and modeling technologies. The first is the use by the Southeast Region Freeways (SRF) team, which handles major interstate projects for urban areas in the southeast region of Wisconsin. The second approach to modeling and visualization is for statewide use. Overall, the Wisconsin DOT uses visualization and modeling technologies to create projects as models and to simulate the construction. By using visualization software and overlaying the model with photogrammetry, drive-through simulations and AR fly-overs of a project are created showing the final product.

\section{Findings and discussion}

A literature review, survey questionnaire of DOTs, and case studies of select DOTs provided the data for this study. The authors analyzed the data collected to identify the uses and challenges of visualization and modeling technologies that DOTs employ for delivering highway infrastructure construction projects. The following sections present the key findings from this study in detail.

\subsection{Use of visualization and modeling technologies}

Figure 2 shows the use of visualization and modeling technologies by DOTs for highway construction delivery. Of the 41 DOT responses collected, 26 are implementing, nine are considering implementation, and six are not implementing visualization and modeling technologies. Of the 35 DOTs that implemented or are considering to implement visualization and modeling technologies, 22 (63\%) responded that they implement LiDAR while eight (23\%) are considering LiDAR implementation. Then, 21 (60\%) implemented and five (14\%) are considering to implement BIM. Only four or fewer DOTs (11\% or less) reported the use of VR, AR, virtual prototyping, wearable visualization devices, and $3 \mathrm{D}$ printing as all these technologies are in their infancy stage regarding their use in highway construction.

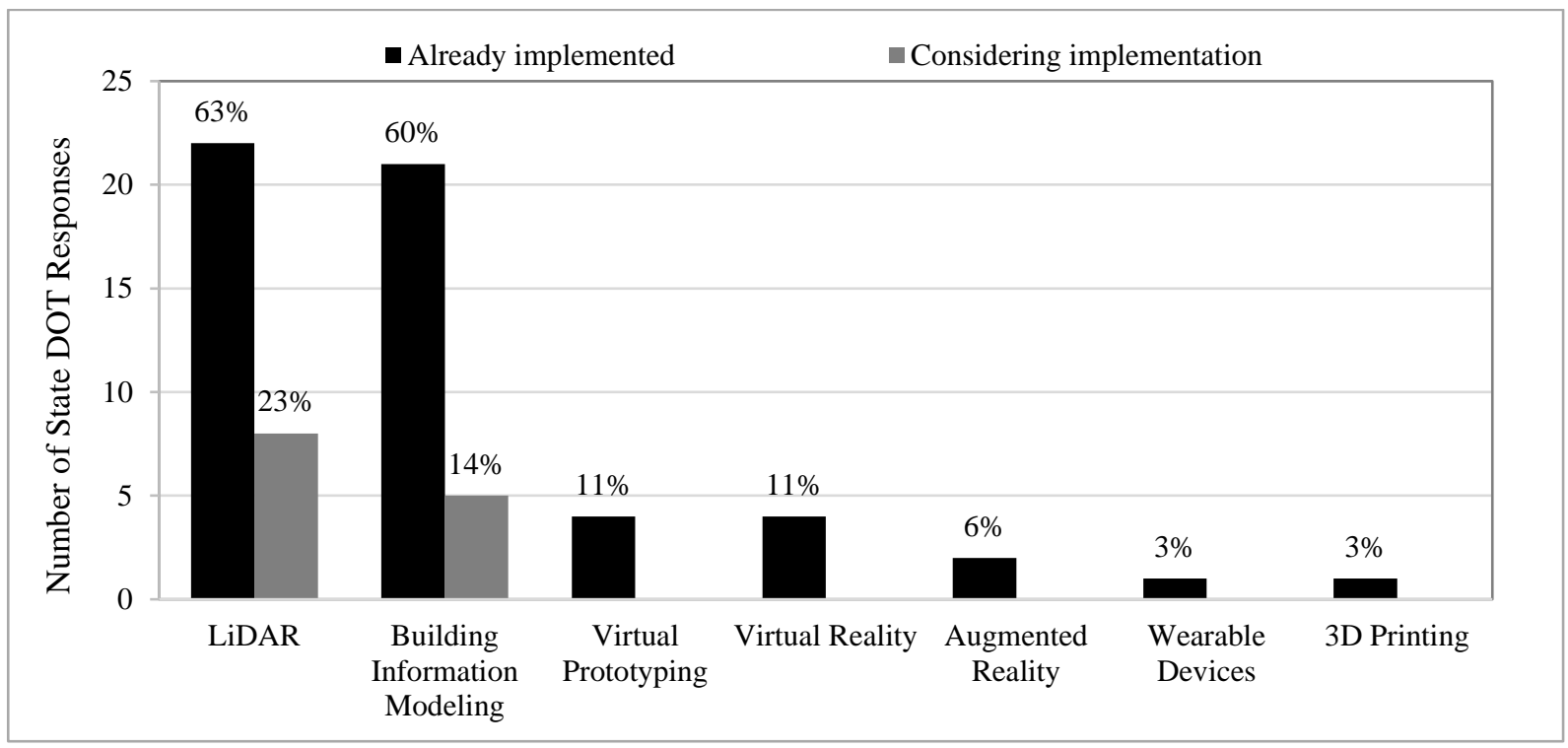

Figure 2. Visualization and modeling technologies implemented by DOTs 
Table 2 summarizes the types of construction tasks that involve visualization and modeling technologies. Twenty-one out of 26 state DOTs, reported using visualization and modeling technologies for constructability reviews. At least one-third of the 26 DOTs noted implementing these technologies for documenting as-built plans and models, simulating construction of bridges and structures, and performing quality control/quality assurance. During the case studies, Pennsylvania DOT mentioned their contractors use 3D models for construction activities that include detailing quantities, automated machine guidance (AMG) for paving and earthwork activities, investigating potential constructability issues before performing the work, and simulating various crane setups and milling operations.

Table 2. Reported uses of visualization and modeling technologies

\begin{tabular}{|c|c|c|c|c|c|c|c|c|c|c|c|}
\hline & 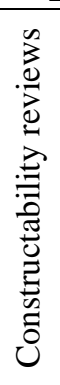 & 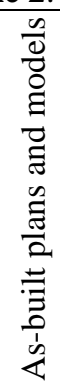 & 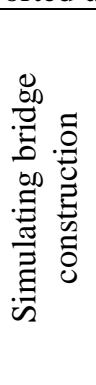 & $\underset{\mho}{\circlearrowright}$ & 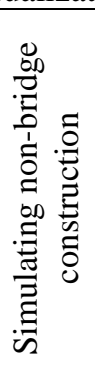 & 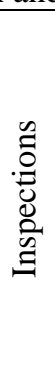 & 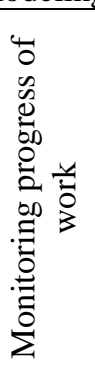 & 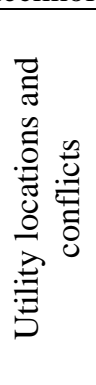 & 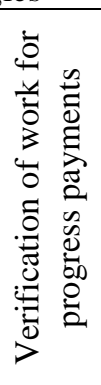 & 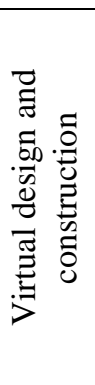 & 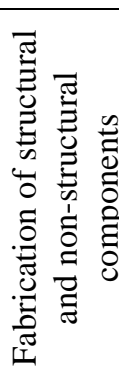 \\
\hline Alabama & $\mathrm{X}$ & $X$ & $\mathrm{X}$ & $\mathrm{X}$ & $\mathrm{X}$ & & $X$ & $\mathrm{X}$ & & & $X$ \\
\hline Arizona & $\mathrm{X}$ & $X$ & & & & & $\mathrm{X}$ & $\mathrm{X}$ & & & \\
\hline Colorado & $\mathrm{X}$ & & & & & & & & & & \\
\hline Delaware & & & & $\mathrm{X}$ & & $\mathrm{X}$ & $\mathrm{X}$ & $X$ & & $X$ & \\
\hline Iowa & $\mathrm{X}$ & & $\mathrm{X}$ & & $\mathrm{X}$ & & & & & & \\
\hline Kentucky & & $\mathrm{X}$ & & $\mathrm{X}$ & & & & & & $\mathrm{X}$ & \\
\hline Maine & $\mathrm{X}$ & $X$ & $\mathrm{X}$ & $X$ & $\mathrm{X}$ & & $\mathrm{X}$ & & $\mathrm{X}$ & $\mathrm{X}$ & \\
\hline Massachusetts & $\mathrm{X}$ & & $\mathrm{X}$ & & $\mathrm{X}$ & & $\mathrm{X}$ & & $\mathrm{X}$ & & \\
\hline Minnesota & $\mathrm{X}$ & $\mathrm{X}$ & $X$ & $\mathrm{X}$ & $X$ & $\mathrm{X}$ & $\mathrm{X}$ & & & $\mathrm{X}$ & \\
\hline Missouri & $\mathrm{X}$ & $X$ & & & $X$ & & $\mathrm{X}$ & & $\mathrm{X}$ & & $\mathrm{X}$ \\
\hline Nebraska & & & & & $\mathrm{X}$ & & & & & & \\
\hline New Hampshire & $\mathrm{X}$ & & & & & & & & & & \\
\hline New York & $\mathrm{X}$ & $\mathrm{X}$ & $\mathrm{X}$ & $X$ & $X$ & $\mathrm{X}$ & $\mathrm{X}$ & & & & \\
\hline Ohio & $\mathrm{X}$ & & $\mathrm{X}$ & $\mathrm{X}$ & $\mathrm{X}$ & $\mathrm{X}$ & & $X$ & & & \\
\hline Oregon & $\mathrm{X}$ & & & & & $\mathrm{X}$ & & & & & \\
\hline Pennsylvania & $\mathrm{X}$ & $\mathrm{X}$ & & & & & & & $X$ & & \\
\hline Rhode Island & $\mathrm{X}$ & & $\mathrm{X}$ & & & & & & & & \\
\hline South Carolina & $\mathrm{X}$ & & & $\mathrm{X}$ & & $\mathrm{X}$ & & & & & \\
\hline South Dakota & $\mathrm{X}$ & & & & & & & $\mathrm{X}$ & & & \\
\hline Tennessee & $\mathrm{X}$ & $\mathrm{X}$ & & & $\mathrm{X}$ & & & $X$ & & & \\
\hline Texas & & & $\mathrm{X}$ & & & & & & & & \\
\hline Utah & $\mathrm{X}$ & & $\mathrm{X}$ & & & $\mathrm{X}$ & $X$ & $\mathrm{X}$ & $\mathrm{X}$ & & \\
\hline Washington & $\mathrm{X}$ & & & & & & & & & & \\
\hline West Virginia & & $\mathrm{X}$ & & & & & & & $\mathrm{X}$ & & \\
\hline Wisconsin & $\mathrm{X}$ & & & $\mathrm{X}$ & & $\mathrm{X}$ & & & & $X$ & $\mathrm{X}$ \\
\hline Wyoming & $\mathrm{X}$ & & & & & & & & & & \\
\hline TOTAL & 21 & 10 & 10 & 9 & 9 & 9 & 9 & 7 & 6 & 5 & 3 \\
\hline
\end{tabular}

DOTs noted several specific project characteristics that they use to determine when to employ visualization and modeling technologies, as shown in Table 3. The Massachusetts DOT uses visualization and modeling technologies for major projects that have a significant impact on motorists. Tennessee DOT employs visualization and modeling technologies for projects in urban regions that involve many utilities and conflicts. Ohio DOT uses visualization and modeling for projects that involve major reconstruction or structural work. Pennsylvania DOT uses visualization and modeling technologies for large earthwork projects, which helps to determine the materials needed and other materials that are not necessary. Alaska DOT noted that they use visualization and modeling technologies for remote location projects, while Nebraska DOT reported that about $50 \%$ of all their projects use them for construction delivery. 
Table 3. Project characteristics suitable for visualization and modeling technologies

\begin{tabular}{ll}
\hline Project Characteristics & State DOT \\
\hline Projects with large or complex scope & Alabama; Colorado; Delaware; Massachusetts; New York; \\
& Ohio; Pennsylvania; Rhode Island; Washington \\
Pilot projects & Alabama; New Hampshire; Ohio \\
Projects using Design-Build & Arizona; Missouri; Ohio \\
Projects using Public-Private Partnerships & Arizona \\
Projects with bridges and structures & Iowa; New York; Rhode Island; Utah \\
Projects with large earthwork quantities & Montana; Nebraska; Pennsylvania; South Carolina \\
Projects with drainage and grading scope & Kentucky; Montana \\
\hline
\end{tabular}

\subsection{Use by stakeholders and project types}

As various project participants engage in the delivery of highway construction projects, Figure 3 illustrates the construction project participants using visualization and modeling technologies. The DOT and the contractor are the two organizations commonly using visualization and modeling tools for highway construction projects, while subcontractors use it about one-third of the time.

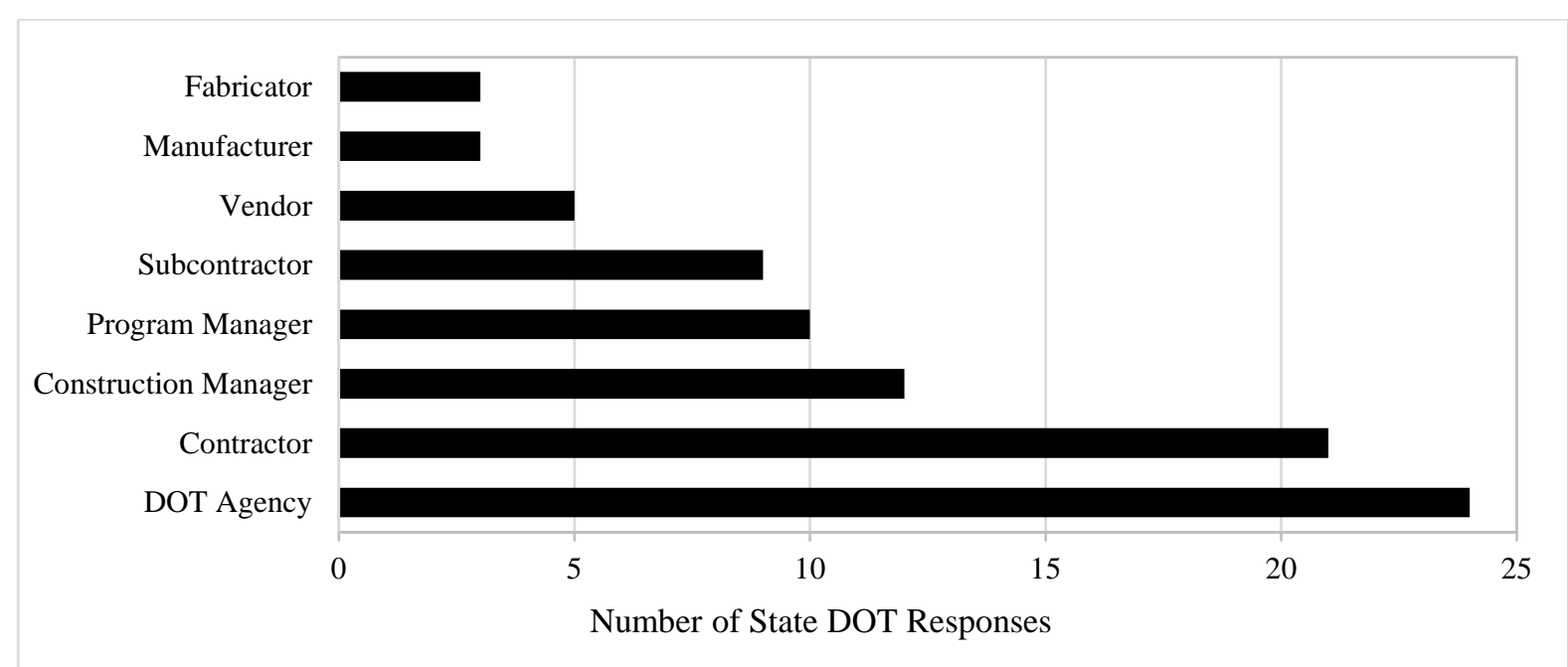

Figure 3. Construction project participants using visualization and modeling technologies

Further, DOTs provided information on the types of work that benefit from the use of visualization and modeling technologies. Figure 4 shows projects that involve drainage and bridge work benefit the most from using visualization and modeling technologies. The Utah DOT and Rhode Island DOT employ visualization and modeling technologies for constructing bridges, which helps to stage and sequence the work in more detail. Massachusetts DOT noted the use of visualization and modeling technologies for drainage work in highway projects that significantly influence traffic, which helps the project team to schedule the work more efficiently.

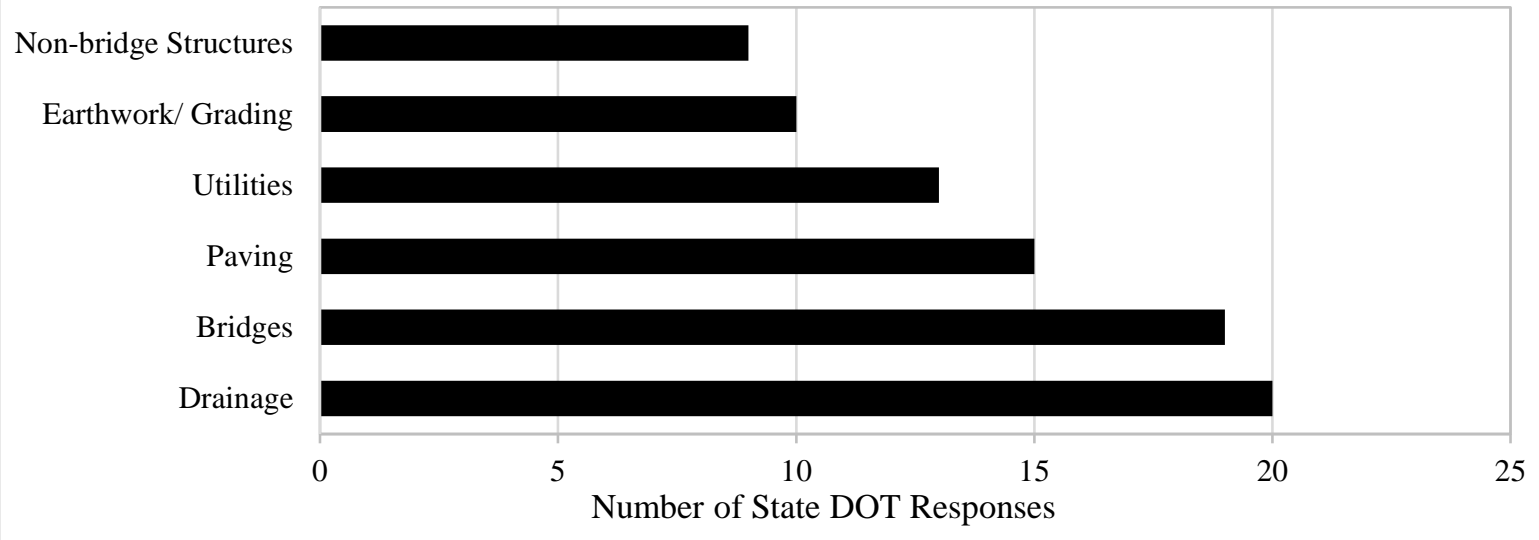

Figure 4. Types of work benefiting from visualization and modeling technologies 


\subsection{Challenges in using visualization and modeling technologies}

Using visualization and modeling technologies has provided a way for DOTs to perform construction tasks more efficiently. However, their use is not without challenges to adoption and use. Table 4 summarizes the challenges found in the collected data and the following sections discuss the primary challenges.

Table 4. Challenges in using visualization and modeling technologies

\begin{tabular}{|c|c|}
\hline Challenges & State DOTs Acknowledging the Challenge \\
\hline $\begin{array}{l}\text { Moving from 2D paper-based plans to 3D digital } \\
\text { models as contract documents }\end{array}$ & $\begin{array}{l}\text { Delaware; Minnesota; Nebraska; New York State; } \\
\text { Ohio; Pennsylvania, Utah; Washington State; } \\
\text { Wisconsin }\end{array}$ \\
\hline $\begin{array}{l}\text { Incompatibility of hardware and software between } \\
\text { DOT and contractors }\end{array}$ & $\begin{array}{l}\text { Arizona; Delaware; Georgia; New York State; Ohio; } \\
\text { Pennsylvania; Wisconsin }\end{array}$ \\
\hline $\begin{array}{l}\text { Proper skills and knowledge are needed to use } \\
\text { visualization and modeling technologies efficiently }\end{array}$ & Massachusetts; New York State; Ohio; Pennsylvania \\
\hline $\begin{array}{l}\text { Existing conditions in a model do not match the actual } \\
\text { conditions at the site }\end{array}$ & Alaska; New York State; Tennessee \\
\hline $\begin{array}{l}\text { Moving beyond 3D models to 4D and 5D models, } \\
\text { simulations, and VR and AR. }\end{array}$ & Minnesota; Ohio \\
\hline
\end{tabular}

\subsubsection{Digital models as contract documents}

One of the major challenges found in the literature, the survey questionnaire data, and the case studies was the legal issues in the evolution from paper-based two-dimensional (2D) plans to digital visualizations and models as contract documents. DOTs that use visualization and modeling technologies provide digital models for contractor use as supplementary data. The Minnesota, New York State, Nebraska, and Wisconsin DOTs indicated they provide digital models to contractors for discretionary use. Contractually, 3D models are not a part of the contract documents and the traditional 2D plans still prevail in the case of discrepancies and dispute resolution. Minnesota DOT is currently investigating the process of developing, delivering, and incorporating digital design models as contract documents, while New York State DOT is developing a pilot program to being using digital 3D models as contract documents. Nebraska DOT is currently ramping up its use of digital models and anticipate a time in the near future when these models become contractual. Wisconsin DOT mentioned that many contractual, legal, and internal factors come into play in moving towards digital models as contractual documents.

\subsubsection{Hardware and software incompatibilities}

The Arizona, Delaware, Georgia, and South Carolina DOTs mentioned that the interoperability of software and hardware between the DOT and contracted parties is essential to efficient use. Ohio DOT noted that the incompatibility of software and hardware for visualization and modeling is a concern. Ohio DOT uses a specific brand of software and hardware for visualizations and modeling, but the contractors that work with them use a variety of other products. Currently, Ohio DOT provides files that a contractor can use so that the contractors can take the modeling information and recreate the model in their software system. However, Ohio DOT staff anticipates a move towards providing more usable models to the contractors so that they do not have to recreate the model.

New York State DOT indicated that they are addressing file transfer issues due to the various visualization and modeling software programs and hardware equipment available for use by contractors. Commonly, New York State DOT uses a specific vendor for digital surveying, which uses DWG files. Contractors may use other equipment, which use CSV files. In conversations the New York State DOT had with their contractors on data transfer, an agreement was established to share XML files, as they are useable in most software packages.

\section{Conclusion}

This study provides a current state of practice in terms of DOT use of visualization and modeling technologies such as BIM for infrastructure, LiDAR, VR, and AR for delivery of transportation construction projects. More than half of state DOTs are using visualization and modeling technologies in various capacities. The common applications of visualization and modeling technologies include performing constructability reviews, simulating construction, documenting as-built information, utilizing virtual design and construction, providing information to conduct construction inspections, helping to manage quality, and communicating project information to stakeholders and the traveling public. Each of these tasks has been shown to be performed more efficiently when using visualization and modeling technologies in the delivery of transportation construction projects. 
Challenges exist with the implementation and use of visualization and modeling technologies, as noted by the finding that not every DOT has implemented these technologies. Incompatibility issues exist between the DOT and contracted third parties, which in some cases causes more work than without the use of visualization and modeling. More DOTs are moving towards digital models over 2D plans, but the move is complicated in that DOTs provide digital models as discretionary information since traditional 2D plans are still the contract documents used for resolving conflicts and disputes. Although visualization and modeling technologies have found a place in transportation construction, further development and research are needed to make these technologies more effective and comprehensive to transportation construction projects.

The state of practice investigated and discussed in this study provides a view into the use of visualization and modeling technologies by DOTs for transportation construction. To continue to advance their use, further research can investigate the legal aspects of moving from traditional 2D plan sets to digital models as contract documents. Additionally, compatibility issues between contracting parties as well as the appropriate skills and knowledge that DOT employees need to possess to use visualization and modeling technologies need to be addressed. Understanding the legal aspects, compatibility issues, and necessary skills and knowledge will help DOTs move into the next phase of digital construction delivery.

\section{Acknowledgments}

The Transportation Research Board (TRB) NCHRP Synthesis program sponsored this research. The authors acknowledge and appreciate the information provided by the staff members of the numerous State Departments of Transportation who assisted with this study.

\section{References}

[1] Avsatthi B. Construction industry needs digitized project-management work flows. Archinect Firms. 2017 Mar.

[2] Pistorius C. The impact of emerging technologies on the construction industry. Innovation Insight. 2017;4(17).

[3] Manyika J, Chui M, Miremadi M, Bughin J. A future that works: AI, automation, employment, and productivity. McKinsey Global Institute Research, Tech. Rep. 2017 Jun;60:1-35.

[4] Jang Y, Kim K, Leite F, Ayer S, Cho YK. Identifying the perception differences of emerging constructionrelated technologies between industry and academia to enable high levels of collaboration. Journal of Construction Engineering and Management. 2021;147(10).

[5] Agarwal R, Chandrasekaran S, Sridhar M. Imagining construction’s digital future. Mckinsey \& Company. 2016 Jun.

[6] Federal Highway Administration. Every day counts: Creating efficiency through technology and collaboration. EDC-3 Final Report. 2017 May;1-36.

[7] Federal Highway Administration. Every day counts: An innovation partnership with states. EDC-4 Final Report. 2019 Apr;1-50.

[8] Olsen M, G. Roe G, Glennie C, Persi F, Reedy M, Hurwitz D, Williams K, Tuss H, Squellati A, Knodler M, Guidelines for the Use of Mobile LIDAR in Transportation Applications. Transportation Research Board of the National Academies, NCHRP Report 784. 2013;1-208.

[9] Maier F, Mallela J, Torres H, Ruiz J, Chang G. Automation in highway construction part II: Design guidance and guide specification manual. Federal Highway Administration, Office of Infrastructure Research and Technology, Report No. FHWA-HRT-16-031. 2018;1-130.

[10] Zeybek M. Extraction of Road Lane Marking from Mobile LiDAR data. Transportation Research Record: Journal of the Transportation Research Board. 2021;2675(5):30-47.

[11] Dye Management. Monitoring highway assets with remote technology. Final Report, Michigan Department of Transportation, Final Report. 2014;1-104.

[12] Yen K, Lasky T, Ravani B. Cost-benefit analysis of mobile terrestrial laser scanning applications for highway infrastructure. ASCE Journal of Infrastructure Systems. 2014;20(4).

[13] Sillars D, Ng E, Calvo-Amodio J, Capalbo S. Advanced technology: Return on investment at the Oregon Department of Transportation. An Investigative Report. 2017 Jun.

[14] Dodge Data and Analytics. Smart market report: The business value of BIM for owners. McGraw Hill Construction. 2014.

[15] Federal Highway Administration. Automated machine guidance with use of 3D models. FHWA Tech Brief. 2013 Mar;1-6. 
[16] O’Brien W, Sankaran B, Leite F, Khwaja N, De Sande Palma I, Goodrum P, Molenaar K, Nevett G, Johnson J. Civil integrated management (CIM) for departments of transportation. Transportation Research Board of the National Academies, NCHRP Report 831. 2016;1-74.

[17] Ahmed S. Barriers to implementation of building information modeling (BIM) to the construction industry: A review. Journal of Civil Engineering and Construction. 2018;7(2):107-113.

[18] Behzadan A, Dong S, Kamat V. Augmented reality visualization: A review of civil infrastructure system applications. Advanced Engineering Informatics. 2015;29(2):252-267.

[19] Whyte J, Nikolic D. Virtual reality and the built environment, Second Edition. Routledge. 2018.

[20] Han B, Leite F. Measuring the Impact of Immersive Virtual Reality on Construction Design Review Applications: Head-Mounted Display versus Desktop Monitor. Journal of Construction Engineering and Management. 2021;147(6).

[21] Azuma R, Baillot Y, Behringer R, Feiner S, Julier S, MacIntyre B. Recent advances in augmented reality. Journal of Computer Graphics and Applications. 2001;21(6):34-47.

[22] Rankohi S, Waugh L. Review and analysis of augmented reality literature for construction industry. Visualization in Engineering. 2013;1(9).

[23] Shin D, Dunston P. Identification of application areas for augmented reality in industrial construction based on technology suitability. Journal of Automation in Construction. 2008;17(7):882-894.

[24] Georgel P, Schroeder P, Benhimane S, Hinterstoisser S, Appel M, Navab N. An industrial augmented reality solution for discrepancy check. In: $20076^{\text {th }}$ IEEE and ACM International Symposium on Mixed and Augmented Reality. 2007 Nov 13. p.111-115.

[25] Golparvar-Fard M, Peña-Mora F, Arboleda CA, Lee S. Visualization of construction progress monitoring with 4D simulation model overlaid on time-lapsed photographs. Journal of computing in civil engineering. 2009;23(6):391-404.

[26] Liu D, Xia X, Chen J, Li S. Integrating building information model and augmented reality for drone-based building inspection. Journal of Computing in Civil Engineering. 2021;35(2):04020073.

[27] Oppenheim A. Questionnaire design, interviewing and attitude measurement. Continuum. 2000.

[28] Government Accounting Office. Using structured interviewing techniques. GAO/PEMD-10.1.5. U. S. 1991.

(C) 2021 by the author(s). This work is licensed under a Creative Commons Attribution 4.0 International License (http://creativecommons.org/licenses/by/4.0/). Authors retain copyright of their work, with first publication rights granted to Tech Reviews Ltd. 